\title{
Estimating willingness-to-pay for the tap water quality improvement in Busan using contingent valuation method
}

\author{
조건부가치측정법을 이용한 부산시 상수도 수질개선에 대한 WTP 추정
}

\author{
Pyo, Heedong ${ }^{1^{*}} \cdot$ Choo, Jae Wook ${ }^{2}$
}

표희동 $1^{*} \cdot$ 추재욱 $^{2}$

${ }^{1}$ Professor, Dept. of Marine Business and Economics, Pukyong National Univ. · ${ }^{2}$ Dept. of Economics, Pukyong National Univ. 1부경대학교 해양산업경영학과 교수 · ${ }^{2}$ 부경대학교 대학원 자원경제학과 졸업

\begin{abstract}
The paper is to estimate willingness-to-pay (WTP) for tap water quality improvement in Busan, using parametric approach in contingent valuation method(CVM). For parametric approach linear logit model and log logit model are employed in double-bounded dichotomous choice format of CVM. For the reliability and the validity of contingent valuation method a survey was conducted for 665 respondents, who were sampled by stratified random sampling method, by personal interview method. The result of mean WTP for the tap water quality improvement in Busan was estimated to be 3,687 won and 3,660 won per month per household, while median WTP being 1,884 won and 1,892 won per month per household, respectively by linear logit model and log logit model. Provided that our sample is broadly representative of the Busan's population, an estimate of the annual aggregated benefit of residential water improvement for all Busan households is approximately 29.7 billion won to 29.8 billion won based on median WTP.
\end{abstract}

Key words : Contingent Valuation Method, Parametric approach, Tap Water Quality Improvement, Willingness-to-Pay(WTP) 주제어 : 조건부가치측정법, 모수추정법, 상수도 수질개선, 지불의사액

\section{1. 서 론}

1990년대 이전과는 달리 1992년 1월 더블린 국 제물환경회의 및 1992년 6월 리우데자네이루 환 경개발회의를 발판으로 "환경적으로 건전한 수자 원관리”라는 국제적 공감대가 형성되었다. 그 주 요 원인은 "물은 모든 경쟁적 이용에서 경제적 가 치를 가지고 있으며, 물은 반드시 경제재로 인식 되어야 한다"는 더블린 회의의 선언에서 출발한 다. 이는 과거의 공급관리중심과 더불어 수요관 리에 대한 중요성을 강조하는 것으로 수자원의 효

- Received 19 August 2014, revised 13 October 2014, accepted 15 October 2014.

*Corresponding author: Tel : 051-629-5959 Fax : 051-629-5953 E-mail : pyoh@pknu.ac.kr
율적인 분배정책의 필요성을 함축하고 있다. 특히 수요자 측면에서 수자원의 경제적 가치를 고려한 물 관리와 상수도사업과 같은 공공정책사업의 타 당성 판단기준을 위해 수자원에 대한 경제적 가치 를 추정하는 것은 매우 중요하다.

수자원은 용도에 따라 크게 생활용수, 농업용 수, 환경용수 및 레크레이션 용수, 공업용수로 나 뉘며, 본 연구에서는 생활용수를 주 내용으로 다 룬다. 생활용수에 대한 연구는 크게 생활용수 수 요의 가격탄력도 분석과 소비자의 지불의사 추정 으로 나눌 수 있다. 지불의사 추정의 경우는 정부 혹은 물 공급기관이 서비스의 질적 개선 등에 대 한 잠재적인 지불의사액(willingness-to-pay: 
WTP)을 추정하여 사회적인 비용과 편익을 비 교하는 수단으로 이용된다. 또한, 집계된 자료가 아닌 개별가구에 대한 조사자료를 이용하여 특 정지역 주민의 의사를 정책에 반영하는데 유용 한 자료로 이용될 수 있다(Park et al., 2006).

이 논문에서는 생활용수의 가치추정을 위한 방법으로 조건부가치측정법(Contingent $\mathrm{Val}-$ uation Method: CVM)을 사용하고 있다. 이 기법은 공공재 또는 환경재의 가치측정방법으로 분석대상과 관련된 $\mathrm{WTP}$ 를을 직접 이끌어내는 것이 그 특징이다(Mitchell and Carson, 1989; Arrow et al., 1993). 이 기법은 설문조사 시 가 상시나리오를 통해 가상시장을 만든 후 설문지 를 통해 공공재의 공급수준 변화 또는 환경질 변 화에 대해 가상 상황을 설정한다. 이런 조건하에 서 응답자들은 환경질의 가상적 변화에 대해서 어느 정도 지불의사가 있는 지를 응답하게 된다. $\mathrm{CVM}$ 은 그 적용에 있어서 응용사례가 상당히 많 으며, 연구절차는 상당 수준 표준화 되었다.

수질개선과 관련하여 국외의 선행연구 중 Houtven et al. (2007)는 Meta-Analysis를 통해 미국 내의 수질개선에 대한 경제적 가치 평가연구의 분석을 수행하였는데, 1968년 2002년 사이에 발행된 논문은 90개에 이르고, 1,014 개의 수질개선에 대한 가치추정이 이루어 졌음을 언급하였다. 특히, 연구대상은 대부분의 경우 상수원 및 레크레이션 용수 그리고 생활용 수가 대부분인 것으로 나타났다(Desvousges et al., 1987; Jeffrey and Abdelmoneim, 1993; Stenger and Willinger, 1998; Sutherland, 1982).

국내에서도 1990년대 후반부터 수질개선의 편익에 대해 다양한 연구결과들이 발표되었다. 수원지의 수질개선 편익에 대해 추정한 연구는 Yang (1997), Cho et al. (1998), Cho et al. (2001), Eom (2001), Kim and Yoo (2005), Lee et al. (2007), Shin et al. (2009), Ahn and Kwon (2009) 등이 있다. 또한 생활용수의 수질개선 편익을 추정한 연구는 Kwak (1994),
Eom (2000), Kim (2001), Yoo (2003), Yoo et al. (2006), Park et al. (2006), Yoo and Hong (2007) 등이 있다.

이 논문은 선행연구에서 도입한 모수추정법 중 선형로짓모형과 로그로짓모형에 의한 조건부 가치측정법을 이용하여 부산시민의 상수도 수질 개선에 대한 $\mathrm{WTP}$ 을 추정한다.

\section{2. 조건부 가치측정법에 의한 설문지 설계 및 운용절차}

설문지는 연구목적에 부합하는 유용한 자료 의 수집을 위한 수단으로, 분석에 필요한 정보의 종류와 설문방법, 분석내용과 분석방법 등을 고 려하여 작성해야 분석이 용이하고, 쉽게 결론을 유도할 수 있다. 특히, 조건부 가치측정법에서는 대상재화에 대한 시나리오가 얼마나 이해가능하 고 설득력이 있으며, 의미부여가 잘 되었는지와 실사단계 등 설문조사의 전 단계를 걸쳐서 얼마 나 과학적이고, 실용적으로 이루어졌는지의 여 부에 따라 설문조사의 신뢰성과 타당성을 확보 할 수 있다(Pyo et al., 2001).

이와 같이 조건부 가치측정법의 WTP 추정은 전적으로 설문조사에 의존하며, 분석결과는 작 성방법에 따라 민감한 영향을 받는다. 이러한 점 을 고려하여 본 연구의 설문지는 Fig. 1의 절차 를 따라 구성한다.

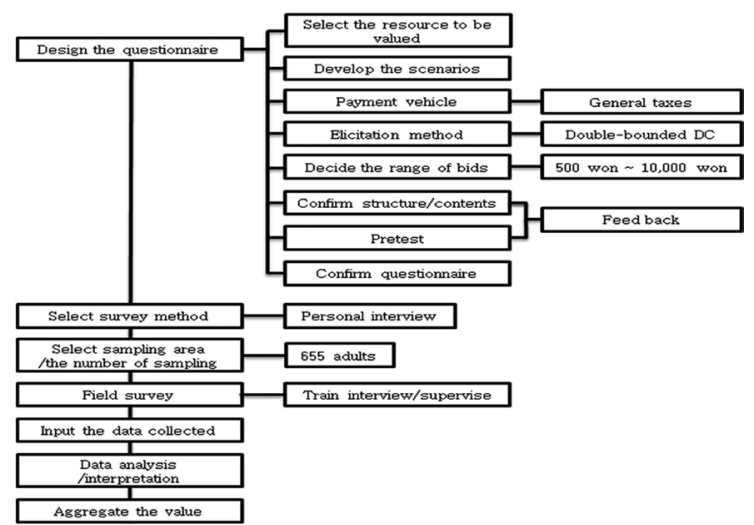

Fig. 1. The framework of survey using CVM 


\section{1 설문지 설계}

1) 대상재화 선정 및 시나리오 작성

조건부가치측정법에 사용되는 설문지는 평가 대상의 설명과 응답자가 처한 가상적 상황에 대 한 설명, 평가대상에 대한 지불의사를 유도하는 질문, 마지막으로 응답자의 사회경제적 특징과 평가대상에 관한 선호 및 이용여부 등에 관한 질 문을 포함한다. 이러한 점을 고려하여 이 논문의 설문지는 대상재화에 대한 일반사항과 사회경제 통계에 관한 사항 및 지불수단을 포함하고 있다.

이 논문에서는 지불수단의 선택으로 “수질개 선부담금”이라는 일종의 세금을 지불수단으로 제시한다. 응답자들에게 지불의사금액을 묻기 전에 다음과 같은 지불의사금액과 관련한 구체 적인 내용을 제시한다. "부산시가 추진 중인 「수 돗물 안심하고 마시기 종합대책」에 따라 식수 전 용댐, 고도정수처리장 등의 건설과 수돗물개선 및 노후관 교체·개량이 충분히 이뤄지면 정수 의 과정없이 집에서 수돗물을 마음 놓고 그냥 마 실 수 있습니다. 이를 위해 필요한 재원은 가구 당 수질개선부담금으로 충당됩니다. 현재 부산 시의 1 톤당 평균 수도요금은 644 원 정도이며, 먹는 샘물(생수)은 2리터 기준으로 약 293원(수 돗물의 227배)입니다. 생수의 경우 음용수로만 사용하지만, 수돗물의 경우 음용수 외에 세탁, 조리, 샤워 등의 용도로 사용한다는 점을 감안해 주시기 바랍니다. 만약 귀하가 수질개선부담금 으로 지불을 동의하신다면 그 금액은 반드시 부 담하여야 합니다. 또한 귀하의 가구의 소득은 제 한되어 있고 그 소득은 여러 용도로 지출되어야 한다는 사실을 고려하신 후 다음 질문에 신중하 게 대답하여 주시기 바랍니다."

질문내용: 귀하의 가정에서는 수질개선부담 금으로 매달 ﹎원을 추가로 지불할 의향이 있 습니까?

2) 지불의사 유도방법 및 제시금액의 선택

이 논문에서는 NOAA의 "blue-ribbon $\mathrm{CV}$ panel”에서 제시한 양분형 질문법으로 지불의사
를 유도하였다(Arrow et al., 1993). 이와 같은 양분형 질문법은 현실시장에서 소비자들의 행동 을 결정하는 유형과 국민투표에서 투표하는 유 형과 유사한 것으로서 Hanemann (1984)에 의 해 그 분석모형이 제시된 이래 큰 설득력을 얻고 있다. 이 논문에서는 단일 양분형에 비해 통계적 효율성이 높은 이중 양분형 설문법을 사용하였 다(Hanemann et al., 1991). Alberini (1995) 는 Cameron and Quiggin (1994)의 이변량 정규분포모형(bivariate normal distribution model)과 Hanemann et al. (1991)의 표준구 간자료모형(standard interval data model) 에 대한 Monte Carlo 분석을 수행하였는데, Hanemann의 모형이 Cameron and Quiggin 의 모형보다 월등한 것으로 주장하였다.

무작위로 추출된 표본의 응답자에게 미리 정 해진 특정금액을 가정에서 매달 지불할 의사가 있는지의 여부를 물어본 후에 “예”라고 응답한 응답자에게는 초기금액의 2 배에 해당하는 금액 을, “아니오”라고 응답한 사람에게는 초기 제시 금액의 $1 / 2$ 에 해당하는 금액을 낼 의사가 있는 지를 물어본다. 그리고 초기 제시금액과 $1 / 2$ 에 해당하는 금액 모두 “아니오”라고 응답한 응답자 에게는 수질개선에 대한 지불의사여부를 물어본 후, 지불의사가 있을 시 그 금액을 직접 기입하 도록 한다. 그리고 전혀 수질개선에 대해 지불의 사가 없는 경우에는 다른 문항에서 질문하여 그 이유를 응답하도록 유도 한다

제시금액의 경우 조건부가치측정법으로 도출 되는 $\mathrm{WTP}$ 의 평균값 및 중앙값에 민감한 영향 을 미치게 된다. 따라서 제시금액의 결정에 있어 세심한 결정이 이루어져야 한다. 본 논문에서는 $\mathrm{K}$-water (2007) 등 관련 국내 논문에서 활용 된 총 11 개의 초기 제시금액을 설정하였으며, 구 체적으로 500 원, 1,000 원, 2,000 원, 3,000 원, 4,000 원, 5,000 원, 6,000 원, 7,000 원, 8,000 원, 9,000 원, 10,000 원으로 한다. 


\section{2 설문방법 및 설문조사}

이 논문에서는 $1: 1$ 개별면접조사 방법을 사용 하여, 부산시 16 개 구의 인구비례를 감안한 층화 무작위 표본추출법(Stratified Random Sampling)을 이용한다. 그 결과 총 665 개의 표본을 획득하였으며, WTP을 추정하기 위한 지불수단 으로 수질개선부담금이라는 가상적 세금을 만들 었기 때문에 표본추출에 있어 학생은 설문대상 에서 제외시켰다.

우선 2009년 7월 25일부터 26일까지 응답자 를 위해 설문지의 이해도 및 완성도를 높일 수 있도록 사전조사를 실시하여 설문지 양식 및 내 용을 수정하였고 조사위원 13명을 선정하였다. 그 후 2009년 8월 8일부터 10월 11일간 약 2개 월 동안 설문조사를 실시하였다.

특히, 연구방법의 특성상 조사원 개개인의 자 질에 따라 결과에 큰 영향을 주기 때문에 본격적 인 설문조사 전에 조사원에게 조사의 목적과 방 법 및 설문지의 내용 등에 대하여 2 차례의 교육 을 실시하였다. 먼저 응답자에게 조사원 개개인 의 소속과 이름을 밝히고, 응답자의 개인정보 유 출에 대해 우려하지 않도록 설문 조사내용은 일 체 비공개로 유지됨을 강조하도록 하였다.

그리고 설문조사를 시행할 시 거부감을 줄이 기 위해 응답자와 조사자가 각각 1 부씩 설문지를 보유하고 조사자는 자신의 설문지를 보면서 응 답자에게 각 문항에 대한 내용을 설명하고, 응답 자 스스로가 각 문항에 개인의 의사를 표현하도 록 강조하였다.

마지막으로 $\mathrm{WTP}$ 을 추정하기 위한 설문지에 서는 조사자가 가상적 상황에 대해서 정확하게 숙지하도록 하여 응답자에게 해당내용을 설명할 때 정확한 WTP에 대한 의사를 응답할 수 있도 록 유도하였다.

\section{WTP 추정모형 설정}

이 논문에서는 Hanemann (1984)이 제안한 효용격차모형(utility difference model)을 이
용하여 WTP을 추정한다. 모형의 운용은 다음 의 절차를 따른다. 우선 제시된 금액에 대해 지 불의사가 있는지 여부를 묻는 질문에 대한 응 답을 모형화한다. 즉, '예' 또는 '아니오'의 이산 응답을 모형화한 후 최우추정법을 통해 관련된 모수들을 추정한다. 다음 단계로 분포의 성격과 평균값 또는 중앙값의 정의를 이용하여 $\mathrm{WTP}$ 의 평균값 또는 중앙값을 계산한다. $\mathrm{WTP}$ 의 추정 은 누적분포함수의 모수를 추정하는 것을 의미 하며, 이 논문에서는 로지스틱분포 혹은 정규분 포를 가정한다.

응답자들이 생활용수의 수질개선을 위해 $A$ 만 큼의 금액을 지불하게 되는 조건은 효용의 격차 $(\Delta v)$ 와 오차항의 격차를 이용하여 다음 식(1)과 같이 정의한다. 여기서 $\mathrm{M}$ 은 소득을 나타내고, 0 은 현재의 생활용수 수질에 대한 상태를, 1 은 수 질개선상태를 의미하고, $\mathrm{S}$ 는 개인의 특성을 나 타낸다.

$$
\begin{aligned}
& \Delta v \equiv v(1, M-A ; S)-v(0, M ; S) \geq \epsilon_{0}-\epsilon_{1} \\
& \eta \equiv \epsilon_{0}-\epsilon_{1}=0
\end{aligned}
$$

$\eta$ 의 누적확률분포함수(Cumulative Distribution Function)를 $F_{n}(\bullet)$ 이라 가정하면 "Yes"라고 응답할 확률은 다음 식(2)와 같이 표 현된다.

$$
\operatorname{Pr}\{Y e s\}=\operatorname{Pr}\{\Delta v \geq \eta\} \equiv F_{\eta}[\Delta v]
$$

"Yes"라는 응답은 $\Delta v \geqq 0$ 일 때 관측되며, “NO"란 응답은 $\Delta v<0$ 일 때 관측되므로 $W$ 로 표 기할 $W P T$ 의 $\mathrm{CDF}$ 는 $F_{W}(\bullet)$ 이다. 한편 식 $(2)$ 는 다음 식(3)과 같이 다르게 표현될 수 있다.

$$
\begin{aligned}
\operatorname{Pr}\{Y e S\}=\operatorname{Pr}\{W & \geq A\} \\
& \equiv 1-\operatorname{Pr}(W<A)=1-F_{W}(A)
\end{aligned}
$$

따라서, 식 (2)와 식 (3)을 비교하면 효용격차 함수와 WTP간에는 다음 식(4)와 같은 관계가 성립함을 알 수 있다.

$$
F_{W}(A) \equiv 1-F_{n}[\Delta v]
$$


결국 $\mathrm{WTP}$ 의 추정은 누적분포함수 $F_{W}$ 의 모수 를 추정하는 것을 의미하며, 식(1)의 이산확률모 형을 적합시켜 $F_{\eta}$ 의 모수를 추정하는 것으로 해 석될 수 있다는 점을 시사한다.

실증분석을 위해 $F_{n}[\Delta v]$ 가 어떤 형태를 나타 내는지에 대해 추가적인 가정이 필요하다. 일반 적으로 $\eta$ 에 대해서 로지스틱분포 혹은 정규분포 를 가정한다. 전자의 경우를 로짓(logit)모형, 후 자를 프로빗(probit)모형이라고 한다. 두 모형 의 추정결과는 거의 유사하지만 추정결과로부터 가치측정 계산이 로짓모형에서 비교적 용이하기 때문에 로짓모형이 많이 이용되며 본 논문에서 도 로짓모형으로 분석한다.

따라서 여기서는 $\eta$ 의 분포를 로지스틱 분포로 가정할 경우 $F_{\eta}$ 는 식(5)와 같이 로지스틱함수로 나타낼 수 있다.

$$
F_{\eta}[\Delta v]=\frac{e^{\Delta v}}{1+e^{\Delta v}}=\frac{1}{1+e^{-\Delta v}}
$$

따라서 $\mathrm{WTP}$ 의 누적확률분포함수는 다음 식 (6)과 같다.

$$
F_{W}[A]=1-F_{\eta}[\Delta v]=1-\frac{1}{1+e^{-\Delta v}}=\frac{1}{1+e^{\Delta v}}
$$

확률모형 $v(j ; M ; S)$ 에 대한 함수적 형태를 가 정하고 $\Delta v$ 를 계산할 수 있다. 함수의 형태를 선 형함수와 로그함수로 가정하는데, 전자의 경우 선형로짓모형(Linear-logit model)이며, 후자 의 경우 로그로짓모형 $(\mathrm{Log}-\mathrm{logit}$ model)이다. 선형로짓모형을 이용한 확률모형은 다음 식(7) 과 같다.

$$
v(j ; m ; s)=\alpha_{j}+\beta m, \beta>0, j=0,1
$$

그리고 $\Delta v$ 와 확률이산선택모형(statistical discrete choice model) $F_{n}(\cdot)$ 은 다음 식(8) 과 같다.

$\Delta v=v(1, M ;-A ; S)-v(0, M ; S)$

$=\alpha_{1}-\alpha_{0}+\beta(m-A)-\beta m=\alpha-\beta A$ where $\alpha \equiv \alpha_{1}-\alpha_{0}$

$$
\therefore \operatorname{Pr}\{Y e S\}=F_{\eta}(\alpha-\beta A)
$$

무작위로 제시되는 금액 $(\mathrm{A})$ 구간을 0 에서 $\infty$ 까지로 하여 추정되는 확률누적면적인 $\mathrm{WTP}$ 의 평균 $\left(W T P_{\text {mean }}\right)$ 이 이용될 수 있다(Hanemann, 1984). 따라서 WTP의 평균은 다음 식(9)와 같다.

$$
\begin{aligned}
& E(W T P)=W T P_{\text {mean }} \\
& \quad=\int_{0}^{\infty} F_{\eta}(\Delta v) d A=\frac{1}{\beta_{A}} \cdot \ln [1+\exp (\alpha)]
\end{aligned}
$$

다음으로 선형로짓함수로 가정할 경우 누적 확률분포는 음의 영역을 갖게 되어 음의 WTP 을 내포하게 된다. 이러한 관계로 음의 제시금액 (negative bid)면적을 포함한 평균 $\left(W T P_{\text {전체mean }}\right)$ 이 이용된다. 또한 중앙값 $\left(W T P_{\text {median }}\right)$ 은 표준로 짓 모형의 누적확률분포함수에 대해 $F_{n}(0)=0.5$ 이다. 따라서 중앙값은 $\Delta v=\alpha-\beta_{A} \cdot A=0$ 을 만족하는 $A=\alpha / \beta_{A}$ 가 된다. 이는 식(10)과 같 이 $W T P_{\text {전체mean }}$ (overall mean WTP)의 값과 동 일하다.

$$
\begin{aligned}
& E(W T P)=W T P_{\text {전체mean }} \\
& =\int_{0}^{\infty} F_{\eta}(\Delta v) d A-\int_{-\infty}^{0}\left[1-F_{\eta}(\Delta v)\right] d A=\frac{\alpha}{\beta_{A}}
\end{aligned}
$$

식(9)와 (10)에서는 WTP의 분포가 우측의 점 근적 분포가 문제점으로 나타날 수 있다. 이는 소비이론에 위배되며 WTP의 실현가능한 범위 는 실질적이지 않다. 이러한 이유로 인해 제안 되는 평균도출식이 식(11)과 같은 절단 평균값 (truncated mean)개념이다.

$$
\begin{aligned}
& E(W T P)=W T P_{\text {truncated mean }} \\
& =\int_{0}^{\operatorname{Max} A} F_{\eta}(\Delta v) d A \\
& =\frac{1}{\beta}\left[\ln \left|\frac{\exp (\alpha)}{1+\exp (\alpha+\beta \cdot \operatorname{Max} . A)}\right|\right]
\end{aligned}
$$

선형로짓모형의 음의 WTP구간을 포함하는 통계적 문제점을 원천적으로 해결하기 위해 연 속독립변수(제시금액, 소득 등)에 로그를 취하 는 로그로짓모형은 또한 후생척도로서 $\mathrm{WTP}$ 은 단일값이 존재하지 않는다. 로그로짓모형을 활 
용한 확률모형은 다음 식(12)와 같다.

$$
\begin{aligned}
v(j ; m ; s) & =\alpha_{j}+\beta \ln m, \beta>0, j=0,1 \text { 에서 } \quad(12) \quad\left(\alpha \equiv \alpha_{1}-\alpha_{0}\right) \\
\Delta v & =\alpha-\beta \ln \left(1-\frac{A}{m}\right) \quad
\end{aligned}
$$

일반적으로 로그로짓모형에서는 WTP의 대표 값으로 0 에서 무한대까지 추정되는 확률 누적면 적인 $\mathrm{WTP}$ 의 평균과 추정확률함수의 값이 0.5 일 때의 $\mathrm{WTP}$ 인 중앙값, 그리고 $\mathrm{WTP}$ 의 절단된 평 균 등을 이용한다. WTP의 평균을 식으로 나타 내면 다음 식(13)과 같다.

$$
\begin{aligned}
& E(W T P)=W T P_{\text {mean }} \\
& =\int_{0}^{\infty} F_{\eta}(\Delta v) d A=\exp \left(\frac{\alpha}{\beta_{A}}\right) \frac{\frac{\pi}{\beta_{A}}}{\sin \left(-\frac{\pi}{\beta_{A}}\right)}
\end{aligned}
$$

여기에서 $\beta_{A}$ 의 추정치가 $-1<1 / \beta_{1}<0$ 을 만족 시키지 못하면 적분값은 수렴하지 못한다. 또한 $\mathrm{WTP}$ 의 중위수는 추정확률함수의 값이 0.5 일 때 의 금액으로 다음 식(14)와 같다.

$$
E(W T P)=W T P_{\text {median }}=\exp \left(\frac{\alpha}{\beta_{A}}\right)
$$

마지막으로, $\mathrm{WTP}$ 의 절단된 평균은 금액 $\mathrm{B}$ 원 을 극소값 제로 $(0)$ 원부터 극대값 $\mathrm{B}$ 까지의 범위 를 고려하여 계산한다. 극대값의 범위는 경우에 따라서 추정확률 $10 \%, 25 \%$ 혹은 최대제시금액 등을 선택하여 절단시키고, 그 이상의 면적을 제 외하여 측정한다.

주어진 수돗물 수질개선 프로그램에 대해 $i$ 번 째 응답자는 첫 번째 제시금액 $\left(A_{i}\right)$ 을 지불할지 여 부에 대해 "YES" 혹은 "NO"로 응답한다. "YES" 라고 응답한 응답자에게 제시되는 두 번째 금액 과 “NO”라고 응답한 응답자에게 제시되는 두 번 째 금액은 각각 $A_{i}^{H}\left(=2 \times A_{i}\right), A_{i}^{L}\left(=0.5 \times A_{i}\right)$ 로 표시한다. 이러한 질문법에서는 응답자의 유형 은 4가지로 나뉜다. 여기서 다음 식(15)와 같은 지시함수를 정의할 수 있다.

$$
I_{i}^{Y Y}=1(i \text { 번째 응답자의 응답이 "YES - YES") }
$$

$$
\begin{aligned}
& I_{i}^{Y N}=1(i \text { 번째 응답자의 응답이 "YES - NO" }) \\
& I_{i}^{N Y}=1(i \text { 번째 응답자의 응답이 "NO - YES" }) \\
& I_{i}^{N N}=1(i \text { 번째 응답자의 응답이 "NO - NO" })
\end{aligned}
$$

여기서 괄호 안의 조건이 만족되면 1 의 값을 취하고 만족되지 않으면 $\mathrm{O}$ 의 값을 갖는다. 예 를 들어, $I_{i}^{Y Y}$ 는 $i$ 번째 응답자의 응답이 "YES YES"이면 1이고, 아니면 0의 값을 취한다.

우도함수를 유도하기 위해서는 다음 식(16)과 같이 네 가지 경우의 확률을 알아야 한다.

$$
\begin{aligned}
I_{i}^{Y Y}=1 & \rightarrow \operatorname{Pr}\left[W_{i} \geqq A_{i}^{H}\right] \\
I_{i}^{Y N}=1 & \rightarrow \operatorname{Pr}\left[A_{i} \leqq W_{i}<A_{i}^{H}\right] \\
I_{i}^{N Y}=1 & \rightarrow \operatorname{Pr}\left[A_{i}^{L} \leqq W_{i}<A_{i}\right] \\
I_{i}^{N N}=1 & \rightarrow \operatorname{Pr}\left[W_{i}<A_{i}^{L}\right]
\end{aligned}
$$

효용극대화를 추구하는 응답자 $N$ 명의 응답자 에 의한 특정응답 관측치가 관측될 확률은 다음 식(17)과 같은 우도함수로 나타낼 수 있으며, 이 를 통해 $F_{\eta}(\bullet)$ 를 로지스틱 누적확률분포함수로 정형화하여 로지스틱분포함수를 추정할 수 있다.

$\operatorname{In} L=$
$\sum_{i=1}^{N}\left\{\begin{array}{l}I_{i}^{Y Y} \ln \left[1-F_{W}\left(A_{i}^{H}\right)+I_{i}^{Y N} \ln \left[F_{W}\left(A_{i}^{H}\right)-F_{W}\left(A_{i}\right)\right]\right. \\ +I_{i}^{N Y} \ln \left[F_{W}\left(A_{i}\right)-F_{W}\left(A_{i}^{L}\right)\right]+I_{i}^{N N}\left[\ln F_{W}\left(A_{i}^{L}\right)\right]\end{array}\right\}$

\section{4. 분석결과}

\subsection{WTP에 대한 응답분포}

665 개의 표본샘플로 부산시의 생활용수 수질 개선을 위한 WTP을 조사- 분석한 결과 205명 이 수질개선에 대한 WTP이 존재한다고 응답하 였으며, Table 1과 같은 응답분포를 나타내었다. 제시금액별 샘플의 수는 별 차이가 없으며, 제시 금액이 높아질수록 수락응답이 낮아짐으로 경제 학의 기본이론에 부합함을 알 수 있다. 첫 번째 또는 두 번째 제시금액 중 어느 하나의 금액에 대 해 지불의사가 있는 가구수는 총 665 가구수 중 337 가구이고, 지불의사가 없는 가구수는 328 가 
구로 나타났다. 지불의사가 없는 가구의 경우 수 질개선정책에 대한 불신이 가장 큰 이유로 나타 났으며 $(31 \%)$, 추가 세금에 대한 거부감이 두 번 째인 것으로 조사되었다 $(27 \%)$.

Table 1. Distribution of responses by bid amount

\begin{tabular}{|c|c|c|c|c|c|}
\hline \multirow{2}{*}{$\begin{array}{c}\text { First bid } \\
\text { (Won) }\end{array}$} & \multirow{2}{*}{$\begin{array}{c}\text { Sample } \\
\text { size }\end{array}$} & \multicolumn{5}{|c|}{ Number of responses } \\
\cline { 3 - 6 } & YY & YN & NY & NN \\
\hline \hline 500 & 63 & 37 & 8 & 4 & 14 \\
\hline 1,000 & 60 & 32 & 7 & 7 & 14 \\
\hline 2,000 & 60 & 12 & 15 & 12 & 21 \\
\hline 3,000 & 60 & 8 & 14 & 12 & 26 \\
\hline 4,000 & 62 & 4 & 9 & 20 & 29 \\
\hline 5,000 & 61 & 4 & 7 & 18 & 32 \\
\hline 6,000 & 60 & 5 & 11 & 16 & 28 \\
\hline 7,000 & 60 & 5 & 3 & 16 & 36 \\
\hline 8,000 & 54 & 3 & 5 & 8 & 38 \\
\hline 9,000 & 63 & 6 & 3 & 7 & 47 \\
\hline 10,000 & 62 & 2 & 5 & 12 & 43 \\
\hline Totals & 665 & 118 & 87 & 132 & 328 \\
\hline
\end{tabular}

\section{2 추정결과}

실증분석에 앞서 공변량이 있는 모델을 추정 하기 위해 사용된 변수의 정의와 표본 통계는 다 음 Table 2 와 같다.
Limdep 8.0을 이용하여 이중양분형의 분석 결과를 살펴보면 Table 3 과 같다. 특이한 점은 월 평균 수도요금(WAT)이 높은 응답자는 수질 개선부담금에 거부감이 있을 것으로 예상할 수 있지만 분석결과는 계수가 $(+)$ 로 나타났다. 이 는 여러 용도로 수돗물 사용량이 많은 응답자들 은 더 좋은 수질을 원하는 것으로 해석할 수 있 다. 또한 가족인원 수(FAM)가 많을수록 물의 사 용량이 높아 추가되는 수질개선부담금에 거부감 이 있을 것으로 예상되었으나, 가족인원 수로 유 발되는 수돗물 사용량에는 상대적으로 큰 부담 이 없는 것으로 나타났다. 수돗물을 음용(DRI) 하는 사람들이 수질개선에 대한 지불의사가 높 을 것이라 예상되지만, 분석결과로는 수돗물을 음용하는 사람들이 현 수질에 어느 정도 만족하 고 있는 것으로 해석할 수 있다. 마지막으로 수 원의 인지여부 $(\mathrm{KNO})$ 에서는 부호가 음으로 나타 났는데, 이는 수원의 상태가 깨끗하지 않은 것으 로 생각하기 때문에 상수도의 수질개선이 아닌 수원지의 수질에 대한 근원적인 불신으로 해석 할 수 있다. 하지만 이들 네 가지의 특이점 모두 는 유의적이지 않은 것으로 판명되었다.

95\%의 신뢰수준에서 두 모형 모두 응답자의 교육수준과 상수도수질개선 정책에 대한 신뢰도

Table 2. Definition and sample statistics of variables

\begin{tabular}{|c|c|c|c|c|}
\hline Variable & Definition & Mean & Standard deviation & Remarks \\
\hline SEX & male $=1$, female $=2$ & 1.71 & 4.54 & \\
\hline AGE & number of years & 2.83 & 1.158 & \\
\hline WAT & monthly tap water charges & 18.699 & 7.8339 & unit: 1,000 won \\
\hline SPR & monthly drinking water cost to buy & 13.034 & 8.3174 & unit: 1,000 won \\
\hline FAM & number of family members & 3.45 & 1.074 & \\
\hline EDU & education level of the respondents & 3.32 & 0.734 & \\
\hline DRI & drink tap water $=1$, not drink tap water $=0$ & 0.78 & 0.412 & \\
\hline $\mathrm{KNO}$ & acknowledge of reservoir & 0.58 & 0.494 & \\
\hline SAT & satisfaction of tap water quality & 3.33 & 1.174 & \\
\hline DAN & danger level of tap water & 3.47 & 1.181 & \\
\hline $\mathrm{CON}$ & reliability of tap water quality policy & 3.56 & 1.151 & \\
\hline INF & existence of infants in the family & 0.11 & 0.309 & \\
\hline OLD & existence of the aged in the family & 0.10 & 0.301 & \\
\hline INC & monthly income of a household & 300.56 & 122.945 & unit: 10,000 won \\
\hline
\end{tabular}


Table 3. Estimation results for DBDC models

\begin{tabular}{|c|c|c|c|c|c|c|}
\hline \multirow{2}{*}{ Variable } & \multicolumn{3}{|c|}{ Linear-Logit } & \multicolumn{3}{|c|}{ Log-Logit } \\
\hline & Coefficient & t-statistic & $\mathrm{P}[|\mathrm{Z}|>\mathrm{Z}]$ & Coefficient & t-statistic & $P[|Z|>z]$ \\
\hline CONSTANT & $6.29960^{* * * *}$ & 6.896 & 0.0000 & 1.72230 & 1.400 & 0.1616 \\
\hline SEX & -0.24876 & -1.316 & 0.1881 & -0.26768 & -1.402 & 0.1609 \\
\hline AGE & 0.04339 & 0.510 & 0.6101 & 0.04720 & 0.554 & 0.5794 \\
\hline WAT & 0.00026 & 0.023 & 0.9818 & 0.12164 & 0.676 & 0.4993 \\
\hline SPR & $0.01939^{*}$ & 1.800 & 0.0718 & $0.24876^{*}$ & 1.766 & 0.0774 \\
\hline FAM & 0.04879 & 0.638 & 0.5232 & 0.02297 & 0.302 & 0.7627 \\
\hline EDU & $0.37801^{* * * *}$ & 2.725 & 0.0064 & $0.37135^{\text {***** }}$ & 2.663 & 0.0077 \\
\hline DRI & -0.12831 & -0.706 & 0.4800 & -0.13468 & -0.742 & 0.4582 \\
\hline $\mathrm{KNO}$ & -0.22524 & -1.334 & 0.1823 & -0.21849 & -1.294 & 0.1956 \\
\hline SAT & $0.14906^{*}$ & 1.704 & 0.0884 & $0.15935^{*}$ & 1.818 & 0.0691 \\
\hline DAN & 0.11947 & 1.307 & 0.1912 & 0.10574 & 1.153 & 0.2489 \\
\hline $\mathrm{CON}$ & $0.26860^{* * * *}$ & 3.004 & 0.0027 & $0.28590^{* * * *}$ & 3.187 & 0.0014 \\
\hline INF & $0.69338^{* * *}$ & 2.425 & 0.0153 & $0.66711^{* * *}$ & 2.323 & 0.0202 \\
\hline OLD & $-0.76542^{* * * *}$ & -2.919 & 0.0035 & $-0.75011^{* * * *}$ & -2.846 & 0.0044 \\
\hline INC & $0.00351^{* * * *}$ & 5.093 & 0.0000 & $0.91248^{* * * *}$ & 5.320 & 0.0000 \\
\hline BID & $-1.37446^{* * * *}$ & -18.811 & 0.0000 & $-1.38253^{* * * *}$ & -18.770 & 0.0000 \\
\hline Log likelihood & \multicolumn{3}{|c|}{-708.8036} & \multicolumn{3}{|c|}{-706.8528} \\
\hline Chi squared & \multicolumn{3}{|c|}{1417.607} & \multicolumn{3}{|c|}{1413.706} \\
\hline Akaike I.C. & \multicolumn{3}{|c|}{1449.6} & \multicolumn{3}{|c|}{1445.7} \\
\hline
\end{tabular}

***, ** and * indicate significance at the $1 \%, 5 \%$ and $10 \%$ level respectively.

Table 4. Estimation results for DBDC models with significant variables

\begin{tabular}{|c|c|c|c|c|c|c|}
\hline \multirow{2}{*}{ Variable } & \multicolumn{5}{|c|}{ Linear-Logit } & \multicolumn{3}{c|}{ Log-Logit } \\
\cline { 2 - 7 } & Coefficient & t-statistic & P $[|\mathrm{Z}|>\mathrm{z}]$ & Coefficient & t-statistic & $\mathrm{P}[|\mathrm{Z}|>\mathrm{z}]$ \\
\hline \hline CONSTANT & $6.49642^{* * * *}$ & 9.894 & 0.0000 & $2.59312^{* * * *}$ & 2.577 & 0.0100 \\
\hline EDU & $0.38665^{* * * *}$ & 3.281 & 0.0010 & $0.37048^{* * *}$ & 3.116 & 0.0018 \\
\hline CON & $0.40660^{* * *}$ & 5.604 & 0.0000 & $0.41573^{* * *}$ & 5.697 & 0.0000 \\
\hline INF & $0.63906^{* * *}$ & 2.337 & 0.0194 & $0.61206^{* *}$ & 2.230 & 0.0257 \\
\hline OLD & $-0.62507^{* * *}$ & -2.402 & 0.0163 & $-0.62259^{* *}$ & -2.374 & 0.0176 \\
\hline INC & $0.00339^{* * * *}$ & 5.068 & 0.0000 & $0.89268^{* * *}$ & 5.468 & 0.0000 \\
\hline BID & $-1.35903^{* * *}$ & -19.247 & 0.0000 & $-1.36589^{* * *}$ & -19.305 & 0.0000 \\
\hline Log likelihood & \multicolumn{7}{|c}{} & & & -714.8232 & 1429.646 \\
\hline Chi squared & -716.3958 & & 1443.6 \\
\hline Akaike I.C. & 1432.792 & \\
\hline
\end{tabular}

${ }^{* * * *},{ }^{* *}$ and ${ }^{*}$ indicate significance at the $1 \%, 5 \%$ and $10 \%$ level respectively.

와 가족구성 중 유아와 고령자의 유무, 가계소득 이 유효한 것으로 나타났다. 이를 통해 통계적으 로 유의적인 독립변수만을 포함한 최종 추정결 과는 Table 4 와 같다. 추정된 모형을 평가하기 위하여 통계적 검정은 개별독립변수에 검정을 하고 전체에 대해서는 로그우도검정을 하였다.
한편, 이중양분형의 선형로짓 및 로그로짓 모 형의 로그우도값을 통하여 계산한 우도비율 검 정통계량과 $5 \%$ 의 유의수준에서 양측검정을 위 한 임계값은 Table 5 와 같고, 이중양분형의 우 도비율 검정통계량의 값은 또한 양 임계값의 사 이에 있으므로 결정규칙에 따라 귀무가설 $\left(H_{0}\right)-$ 
Table 5. Log-likelihood test for DBDC models

\begin{tabular}{|c|c|c|}
\hline \multicolumn{3}{|c|}{ DBDC models } \\
\hline Items & Linear logit & Log-logit \\
\hline Log-likelihood statistics & 15.1844 & 15.9408 \\
\hline Degree of freedom $(=r)$ & 9 & 9 \\
\hline$x^{2}{ }_{10,0.975}$ & 2.70 & 2.70 \\
\hline$x^{2}{ }_{10,0.025}$ & 19.02 & 19.02 \\
\hline
\end{tabular}

Table 6. Monthly WTP in DBDC models

\begin{tabular}{|c|c|c|}
\hline \multirow{2}{*}{ Items } & \multicolumn{2}{|c|}{ DBDC models(unit: won) } \\
\cline { 2 - 3 } & Linear logit & Log logit \\
\hline$W T P_{\text {mean }}$ & 3,687 & 3,660 \\
\hline$W T P_{\text {truncated mean }}$ & 3,025 & 3,011 \\
\hline$W T P_{\text {median }}$ & 1,892 & 1,884 \\
\hline $\begin{array}{c}95 \% \text { confidence } \\
\text { interval of median }\end{array}$ & $1687 \sim 2123$ & $1679 \sim 2113$ \\
\hline $\begin{array}{c}90 \% \text { confidence } \\
\text { interval of median }\end{array}$ & $1718 \sim 2084$ & $1711 \sim 2075$ \\
\hline
\end{tabular}

유의하지 않은 추정계수의 값이 "0"이라는 것이 타당하다.

이중양분형의 선형로짓모형과 로그로짓모형 추정법을 통해 부산시민의 생활용수 수질개선 에 대한 월 평균 $\mathrm{WTP}$ 을 추정한 결과는 Table 6 과 같다. 이중양분형의 경우 선형로짓모형과 로그로짓모형의 평균은 각각 3,687 원과 3,660 원으로 추정되었다. 또한 선형로짓모형과 로그 로짓모형의 절삭된 평균 $\mathrm{WTP}$ 는 각각 3,025 원 과 3,011 원이고, 이들 중앙값은 각각 1,892 원과 1,884 원으로 추정되었으며, 중앙값의 $95 \%$ 신뢰 구간은 각각 1,687 원 2,123원과 1,679 원 2,113원으로 나타났다.

한편, Hanemann(1984)과 Leon(1996)에 따 르면 WTP에 대한 응답자들의 분포가 우측의 긴 꼬리분포 형태로 나타나기 때문에 평균추정치의 경우 분포의 조그만 변화에도 민감하게 변화하 는 반면, 중앙값은 높은 제시금액에도 많은 영향 을 받지 않고 상대적으로 둔감하기 때문에 이러 한 분포의 WTP는 중앙값을 평균의 대표 특성치 로 이용하는 것이 합리적이다. 따라서 이 논문
에서의 WTP는 추정된 중앙값을 토대로 12 개월 수를 곱하고, 이를 다시 2008년 말 기준 부산의 총 세대수 $(1,311,724)$ 를 곱하여 연 평균액을 계 산한다. 그 결과 이중양분형의 선형로짓모형에 의해 추정된 $\mathrm{WTP}$ 는 연간 약 298 억원, 로그로짓 모형에 의한 WTP는 연간 약 297 억원이다.

\section{5. 결 론}

최근 기후변화로 인하여 물 부족 현상에 대한 국제적인 우려가 증대되면서, 그에 따른 연구들 이 진행되고 있다. 특히, 과거의 공급관리중심의 수자원관리와 함께 수요관리측면 또한 그 중요 성이 부각되고 있다. 수자원에 대한 수요 - 공급 관리를 통하여 효율적인 수자원관리체제의 구축 에 국제적인 관심이 집중되면서, 1992년 더블린 에서 열린 국제물환경회의에서는 수자원의 분배 정책이 경제적 가치평가에 의해 분석되어야 한 다는 의미의 선언문까지 발표하게 된다. 따라서 수요관리의 접근 중 가장 중요한 과제라 할 수 있는 수자원에 대한 가치의 인식과 추정에 대해 연구할 필요성이 대두되었다.

생활용수의 공급은 지자체 별로 상이한 수원 지에서 취수하여 이뤼지기 때문에 특히 지자체 별 수자원의 수요관리목적을 위해 지역적 특성 을 고려할 수 있는 자료를 토대로 한 연구가 필 요하다. 본 논문에서는 일반적으로 수질개선에 대한 경제적 편익 추정을 위해 사용되는 조건부 가치측정법을 이용하였다. 이 논문은 이와 같이 부산시 지역 내의 설문조사자료를 통해 모수추 정법으로 생활용수 수질개선에 대한 WTP을 추 정하였다.

설문조사기간은 2009년 8월 8일부터 10월 11 일간 약 2 개월 동안 설문조사를 실시하였으며, 통계적으로 사용가능한 665 개의 표본을 추출하 였다. 이를 통해 이중양분형의 선형로짓과 로그 로짓모형에 의한 모수적 추정방법을 통해 WTP 을 산출하였다. 그 결과 중앙값을 평균의 대표 적 특성치로 활용할 경우 선형로짓모형에 의한 
$\mathrm{WTP}$ 는 가구당 월 평균 1,892 원, 로그로짓모형 에 의한 WTP는 가구당 월 평균 1,884 원으로 나 타났다. 표본결과를 부산시민 전체로 확대할 경 우 생활용수 수질개선에 대한 WTP은 연간 약 297억원 298억원 수준으로 추정되었다. 또한 이 논문에서는 로그우도검증법을 통하여 모수적 방법의 유의한 변수를 선택하는데 있어서 통계 적 유의성을 확보하려는 시도를 하였다.

소득증대에 따른 삶의 질 향상으로 건강에 대 한 관심이 큰 폭으로 상승하면서 만연했던 수돗 물 수질불신의 대체재 역할로 정수기 보급량이 증가하고 있으며, 수돗물의 직접적 음용률은 낮 아지고 있는 실정이다. 이에 따라 상수도 수질 개선 정책의 정책적 당위성을 제시하기 위해 주 민들의 상수도 수질개선에 대한 요구를 인식하 는 것은 중요하다. 따라서 이 논문과 같은 상수 도 수질개선에 대한 WTP은 주민들의 요구를 대 변하는 유용한 정보로 나타날 수 있다. 이 논문 은 생활용수를 관리하는 정책입안자들에게 수질 개선에 따른 경제적 편익 정보를 제공하고, 부산 시 생활용수개선사업의 수행여부나 수행규모를 결정하는 데 있어서 유용한 정보와 시사점을 제 공할 수 있다.

\section{사 사}

이 논문은 2013 학년도 부경대학교의 지원을 받 아수행된 연구입니다. (PK(PKS)-2013-0327).

\section{References}

Ahn, S.Y. and Kwon, H.T. (2009) Research Papers: Application of Contingent Valuation Method for Benefit Evaluation on Improving the Quality of Water, KSWST J. Water Treatment, 17, pp.171-192.

Alberini, A. (1995) Efficiency vs Bias of Willingness-to-Pay Estimates: Bivariate and Interval-Data Models, Journal of Environmental Economics and Management, 29, pp.169-180.
Arrow, K., Solow, R., Portney P.R., Leamer, E.E., Rader, R. and Schuman, H. (1993) Report of the NOAA Panel on Contingent Valuation, Federal Register, 58, pp.46014614.

Cameron, T.A. and Quiggin, J. (1994) Estimation Using Contingent Valuation Data from a Dichotomous Choice with Follow-up Questionnaire”, Journal of Environmental Economics and Management, 27, pp.218234.

Cho, H.J., Lee, B.N. and Kim, J.S. (1998) Assessing the Benefits of Water Quality Improvements Using Contingent Valuation Method: Case Study of the Kumgang Area, Industrial Engineering, 11, pp.209-218.

Cho, Y., Kim, B.K. and Kwak, J.E. (2001) Estimation of WTP for Water Quality Improvements in Paldang Reservoir Using Contingent Valuation, Environmental and Resource Economics Review, 10, pp.433459 .

Desvousges, W.H., Smith, V.K. and Fisher, A. (1987) Option Price Estimates for Water Quality Improvements: A Contingent Valuation Study for the Monongahela River, Journal of Environmental Economics and Management, 14, pp.248-267.

Eom, Y.S. (2000) Valuing Drinking Water Risk Reductions Using Experimental Market Method, Environmental and Resource Economics Review, 9, pp.747-771.

Eom, Y.S. (2001) Empirical Evidence on Scope Effects in Contingent Valuation of $\mathrm{Wa}-$ ter Quality Improvements in Man Kyoung River, Environmental and Resource Economics Review, 10, pp.387-412.

Hanemann, W. (1984) Welfare Evaluations in Contingent Valuation Experiments with Discrete Responses, American Journal of Agricultural Economics, 66, pp.332-341.

Hanemann, W.M., Loomis, J.B. and Kaninnen, B.J. (1991) Statistical Efficiency of Double Bounded Dichotomous Choice Contingent Valuation, American Journal of Agricultural Economics, 73, pp.1255-1263. 
Houtven, G.V., Powers, J. and Pattanayak, S.K. (2007) Valuing Water Quality Improvements in the United States Using Meta-Analysis: Is the Glass Half-full or Half-empty for National Policy Analysis?, Resource and Energy Economics, 29, pp. 206-228.

Jeffrey L.J. and Abdelmoneim, H.E. (1993) Willingness to Pay for Improvements in Drinking Water Quality, Water Resource Research, 29, pp.237-245.

Kim, J.H. (2001) Benefit Estimation of Tap Water Quality Improvement Based on Citizens Willingness-To-Pay, Korean Public Administration Review, 10, pp.245-262.

Kim, Y.J. and Yoo, Y.S. (2005) Valuing Nonmarket Benefits of Water Quality Improvements in Paldang Reservoir and Han River: a Choice Experiments Study, Environmental and Resource Economics Review, 14. pp.337-379.

K-Water(Korea Water Resources Corporation). (2007) $21^{\text {st }}$ Century Frontier R\&D Program for Securing Sustainable Water Resources: Building the System for Water Resources \& Technology Valuation, Ministry of Science and Technology.

Kwak, S.J. (1994) Contingent Valuation of Improving Safety of Tap Water Quality in Seoul, The Korea Spatial Planning Review, 21, pp.23-40.

Lee, J.S., Yoo, S.H. and Kwak, S.J. (2007) Measuring the Economic Benefits of Water Quality Improvement of Nakdong River - Using One-half Bound Dichotomous Choice Model, Economic Research, 25, pp.111-129.

Leon, C. (1996) Double Bounded Survival Values for Preserving the Landscape of Natural Parks, Journal of Environmental Management, 46, pp.103-118.

Mitchell, R.C. and Carson, R.T. (1989) Using Surveys to Value Public Goods: The Contingent Valuation Method. RFF Press.

Park, D.H., Park, Y.S. and Lee, K.M. (2006) Consumer's Willingness to Pay for Residential Water and It's Policy Implication,
J. Korea Water Resources Association, 39, pp. 563-574.

Pyo, H.D., Yoo, S.H. and Kwak, S.J. (2001) Estimating the Conservation Value of Coastal Wetlands around the Youngsan River: The Application of Double-bounded Dichotomous Choice Format of the Contingent Valuation Method, J. the Korean Regional Science Association, 17, pp.37-54.

Shin, H.J., Jeon, C.H., Choi, I.C. and Yeon, I.C. (2009) Estimation of Beneficiary's Willingness to Pay in Mid · down-stream Area to the Water Quality Improvements in upper Bukhan River Basin, Seoul Urban Studies, 10, pp.91-106.

Stenger, A. and Willinger, M. (1998) Preservation Value for Ground water Quality in a Large Aquifer: A Contingent Valuation Study of The Alsatian Aquifer, Journal of Environmental Management, 53, pp.177-193.

Sutherland, R.J. (1982) A Regional Approach to Estimating Recreation Benefits of Improved Water Quality, Journal of Environmental Economics and Management, 9, pp. 229-247.

Yang, J.W. (1997) Estimating Environmental Benefit of Water Quality Improvement in Lake Paldang with Contingent Valuation Method, J. Korea Planners Association, 32, pp. 195-208.

Yoo, S.H. (2003) Analysis of Double-bounded Dichotomous Choice Format of the Contingent Valuation Method Using Sample Selection Model, Review of Fiscal Studies, 10, pp. 47-80.

Yoo, S.H., Shin, C.O. and Yang, C.Y. (2006) Household's Willingness to Pay for Piped Water Quality Improvement in Wonju, $J$. Environmental Policy, 5, pp.9-103.

Yoo, S.H. and Hong, P. (2007) Using a Model of Correcting Missing Response Observation to Measure the Economic Benefits of the Tap Water Quality Improvements in Seoul, Seoul City Research, 8, pp.1-54. 